\title{
ANNOUNCEMENT
}

\section{Online First publication of Oral Radiology}

The editors of Oral Radiology and Springer are pleased to announce the introduction of Online First service for the quick online publication of articles shortly after receipt of the corrected proofs.

Online First publishes accepted articles in electronic form prior to the appearance of the printed journal, without having to wait for the completion of an entire issue, printed or electronic. The electronic version of all articles will be available to subscribers via the Internet weeks before the printed version appears. This means a significant reduction in publication time. It will not be necessary for manuscripts to wait until the next available print issue.

As each article becomes ready for Online First publication, it will be published on the Web with its own publication date. Each article will receive a permanent, unique international identification code, the digital object identifier (DOI), which is registered with the International DOI Foundation (http://www.doi.org). Contributions published Online First, but not yet available in print, may be cited by journal title and DOI only. Furthermore, the DOI forms part of the article's URL (Web address) and can be used to access the article before the print version has appeared. The DOI is never changed and can be used, for example, to create hyperlinks between Online First articles. The print version also includes the DOI and date of online publication.

The appearance of an Online First article online constitutes official publication, so articles cannot subsequently be changed or withdrawn. Any corrections that might be necessary will be in the form of an Erratum, which will be hyperlinked to the article.

Keiji Tanimoto

Editor-in-Chief, Oral Radiology

Springer 